Alexander, Elitsa; Eppler, Martin J. \& Bresciani, Sabrina (2016) Visual Replay

Methodology: A Mixed Methods Approach for Group Discussion Analysis. Journal of Mixed Methods Research (online first). ISSN 1558-6898

Available online at: http://journals.sagepub.com/doi/abs/10.1177/1558689816664479

\title{
Visual Replay Methodology: A Mixed Methods Approach for Group Discussion Analysis
}

\begin{abstract}
In this paper we propose an innovative mixed methods research (MMR) technique and discuss its theory and applications. The visual replay methodology (VRM) is a new graphic way to investigate the discourse patterns during software-aided small-group discussions. A visually supported conversation is recorded through screen capturing and replayed to reconstruct how the discussion has unfolded. The VRM responds to the "integration challenge" that the MMR community is facing - by employing the power of visualization, data integration is leveraged to a new level, where visual synergy gains enable a "value added" research outcome. By employing multi-genre integration and a moderately pragmatic approach, the VRM reduces the researchersubject power-relation gap and contributes to some long-standing MMR debates regarding reflexivity and participation.
\end{abstract}

Keywords: mixed methods; small group communication; discussion replay; visual 


\section{INTRODUCTION}

People hold small-group conversations every day, in collocated and remote settings. In both settings people often choose to manage their conversations visually (Isenberg et al., 2011, p.1; Meyer, Höllerer, Dennis, \& van Leeuwen, 2013, p.489) - they use digital mind maps and concept maps for collaborative sense making, draw project plan diagrams and process maps for planning and workflow design, and refer to argument maps for their problem solving and strategizing. We are witnessing an "unprecedented rise in the use of visuals” (Meyer et al., 2013, p.489) for group discussions. There is a growing realization in management and organizational studies (MOS) that both the process and outcome of visually-supported discussions should be investigated in depth - the conversations which evolve around visuals (like mind maps, timelines, etc.) are as important as the final visual output (see Stigliani \& Ravasi, 2012; Yakura, 2002).

The time has come for a research methodology which provides the means to analyze the processes that shape visual conversations. We believe that the latter methodological goal can only be achieved credibly by utilizing the scholarly accomplishments of mixed methods research (MMR). A mono-method approach would be inadequate - by solely looking at quantitative data (e.g., content analysis of visual conversations with text mining systems like, for instance, QDA Miner, see Fielding, 2012) researchers may miss valuable observations about the conversation dynamics, which would deprive them of the ability to look into the processes that shaped the conversation; on the other hand, a wholly qualitative study may miss potential correlations that are best analyzed statistically.

In this paper we advance the visual replay methodology (VRM) which utilizes a MM embedded design (see, e.g., Creswell \& Plano Clark, 2010; Tashakkori \& Teddlie, 2010). The underlying data is derived from replay recordings of the visual conversation, which can be 
watched and coded by the researchers for the purposes of hypotheses testing (i.e., quantitizing QUAL data) and critical interpretation. With this, the VRM contributes towards alleviating one of the key challenges of visual methodology, namely "how to combine qualitative data sets with epistemologically acceptable and rigorous analysis techniques” (Wall, Higgins, Remedios, Rafferty, \& Tiplady, 2013, p.22). The latter is, admittedly, a key challenge of qualitative research (Fielding, 2012). The VRM thus responds to the "integration challenge” which the mixed methods community is facing, as outlined in Fetters \& Freshwater (2015, p.115) - with our intentional choice to use the power of visualization through the VRM, we aim at leveraging data integration to a new level, where visual synergy gains enable a "value added" research outcome.

The VRM is also in line with one of the distinguishing characteristics of MMR, as outlined in Creswell and Plano Clark (2010) and Tashakkori and Teddlie (2010) - namely, that MMR is particularly amenable to visual analysis through graphical representations. The current knowledge about the incorporation of visual data in mixed methods needs a fresh look by using the "new technologies” (Fielding, 2012) thoughtfully to elicit inferentially credible observations and findings. The VRM is applicable in various settings like planning, workflow design, problem solving, decision making, strategizing, negotiating, and collaborative sense making. Beyond the MOS field, the VRM can be applied to analyze any visually-supported conversation, in any contextual setting.

Figure 1 illustrates the basic terms we are using to describe the VRM. We apply the term “discussants” to refer to the participants in MM-extended controlled experiments, we use the phrase "visual conversation” to describe the process of writing down ideas and opinions on the “shared digital space” provided by a “visual information system”. We apply the term “visual 
template” to describe the graphical canvasses that can (optionally) be used to pre-structure the visual conversation (e.g., a funnel template).

\section{Insert Figure 1 about here}

We start with a literature review and proceed by describing the essentials of the VRM. We then move to the details on the procedure of mixing techniques and the means of achieving methodological integration. We next describe an example study in which the VRM was employed.

\section{LITERATURE REVIEW}

The proliferation and pervasive use of visual information systems has shifted academic attention toward the "visual mode” of discourse and meaning construction (Meyer et al., 2013, 2013, p.489; Bell, Warren, \& Schroeder, 2014; Ewenstein \& Whyte, 2007). Meanwhile, the conflux of two growing areas of technology - collaboration and visualization - into a new research direction, collaborative visualization (Isenberg et al., 2011, p.1), has given rise to a number of visual research methods. Some of these methods are non-participatory - for instance, content analysis, compositional interpretation, semiotics/semiology, and visual discourse analysis (Meyer et al., 2013; Pink, 2013; Rose, 2007). Such methods are concerned with pre-existing visual artifacts which are interpreted much like verbal traces, following an archaeological approach that cannot be compared with the in situ orientation of the VRM.

Another broad stream of visual methods builds upon the array of established participantcentered research methods. For example, visual interviewing (Comi, Bischof, \& Eppler, 2014) builds upon some of the rules of semi-structured interviewing. Visually-supported experiments (Lim, O’Connor, \& Remus, 2005; Stewart \& Stewart, 2001) adopt much of the classical experimental research apparatus. Visually-focused contextual inquiries (Kearney \& Hyle, 2004) 
and ethnographic case studies (Leonardi, 2011; Nicolini, Mengis, \& Swan, 2012) apply

established experience sampling, immersion, and shadowing techniques. Video elicitation

sessions like retrospective analyses of behavior (Miller, 2004; Minneman \& Harrison, 1993) and interviewing supported by video recordings (Henry \& Fetters, 2012) are methods that enhance the accuracy of self-reports.

Video interaction analysis predominantly studies non-verbal behavior, like gestures, personal space, and human traffic (Knoblauch \& Tuma, 2011; Mack, Woodsong, MacQueen, Guest, \& Namey, 2005, p.20; Mondada, 2006; Pink, 2013). The latter naturally imposes a slight shift of focus away from the actual group conversation and is prone to interpretative bias. According to Zeng, Pantic, Roisman, and Huang (2009), many video analysis methods handle deliberate behavior, which is caused by the feeling of "being observed". If camera movements are involved, this implies "selective seeing” and anticipating courses of action. The very practice of adjusting video shots plays an essential role for the identification of expectable patterns of action, as pointed out by Mondada (2006, p.7).

The field of MMR increasingly utilizes the "tremendous potential for making mixed methods relevant to [...] visual methodology” (Creswell, 2009, p.101). Especially prevalent is the use of visuals for the presentation of mixed methods designs, which can be done according to established guidelines (Ivankova, Creswell, \& Stick, 2006) - see, for instance, Evertsson (2015) and Vrkljan (2009). Faithful to its pragmatic orientation, MMR often applies visuals practically, by studying how visual representations are or can be used to support discourse - see, for instance, Jones (2015) and Quinlan and Quinlan (2010). The mono-method-typical instrumental approach (i.e., using visuals to assess effects on outcome variables) is rare in MMR (see Robinson \& Mendelson, 2012), while the methodological approach is amply present. Visual artifacts are often 
employed methodologically, as stimuli in the MM research encounter. For example, Wheeldon (2010) advocates the use of mind maps as data collection tools in mixed methods for capturing integration and inference generation between multiple investigators (Archibald, 2015). Balomenou and Garrod (2015) report how participant-generated images can be used in various investigations of social phenomena. The presence of all of these visual approaches in MMR opens the doors to a fresh look by using the "new technologies” (Fielding, 2012) sensibly to elicit inferentially credible MM observations and findings. Building on the scholarly achievements of MMR, the VRM utilizes the screen recording technology to investigate human conversations in a new way - dynamically, inter-subjectively, and pragmatically, by integrating the accuracy of visually-elicited quantitative counts with the thoughtfulness of qualitative reflections.

\section{OVERVIEW OF THE METHODOLOGY}

The proposed VRM comprises a set of research stages (data collection, coding, and analysis, with their sub-stages, followed by critical interpretation, see Figure 2) during which QUANT and QUAL data are collected in parallel and stored and analyzed sequentially and the results of a phase are used to guide the next phase. For example, the topics to be discussed during the qualitative follow-up can be framed based on the experimental and survey output, the insights gained from overlaying many replay diagrams can be used for hypotheses development, etc. The VRM is suitable for MMR-extended controlled experiments (like the practical example we are presenting below) but can also be applied to enhance other participant-centered research methods, for instance visual interviewing and retrospective analysis of behavior.

Insert Figure 2 about here 
A precondition for applying the VRM is that the discussion contributions (i.e., ideas and opinions) are mapped on a shared digital space (e.g., provided by a visual information system see Table 1 for examples of software tools) - for instance during online or co-located meetings, workshops, decision making or negotiation sessions. The discussion patterns displayed during the group debate - unveiled by the creation, movement and modification of textual elements on the shared digital space - can be replayed from the start to visually reproduce how the conversation has unfolded. Contributions can be traced with regard to timing and trajectory (tracked by means of the mouse cursor path), logical groupings, etc. The shared digital space may be empty (a blank canvas, e.g., on Adobe Connect shared whiteboard) or graphically prestructured by means of software-preloaded visual templates - e.g., concept maps in Cmap, argument maps in Agora, mind maps in Mindjet, process maps in Visio, and a variety of visual templates in let's focus.

Insert Table 1 about here

The visual conversation held on the shared digital space is captured and recorded (step 1 in Figure 2) with the help of an embedded screen recording functionality (e.g., with the let's focus suite) or with the help of screen-recording software (like Adobe Captivate, ALLCapture, CamStudio). Screen recording produces video files (which we refer to as "replay recordings”) in which the visual conversations are salvaged for future referral. The replay recordings are authentic and informative (unlike, for example, meeting minutes, which may often be subjectively shaped).

The replay recordings can be rewound after the discussion to watch the whole visually documented conversation, or selected parts of it, in a qualitative follow-up (step 3 in Figure 2). The interactive features of the replay recordings (user-chosen playback speed, layering 
functionality, etc.) allow for interactive “reviewability” (Clark \& Brennan, 1991). The qualitative data gathered during the follow-up can be compared to the quantitative data from the survey (step 2 in Figure 2). And vice-versa - the topics to be dug into during the follow-up can be inspired based on the survey results. Participants who have given particular answers to survey questions may be purposefully selected and invited to participate in the follow-up, in accord with the procedure proposed in Ivankova (2013, p.41).

Following this, the QUAL data from the replay recordings is transformed into quantitative counts with the help of the coding scheme (Table 2) and stored visually and numerically. The visual storage is done in the form of "replay diagrams” (Figures 4, 5, 6): the historical development of actions (such as adding or moving text) is drawn with lines and symbols according to the coding scheme (Table 2). Numerical storage is done in a "spatiotemporal database” (steps 4 and 5 in Figure 2). The data analysis is first done qualitatively by means of overlaying ${ }^{1}$ many replay diagrams (step 6 in Figure 2). Overlaying reveals visual communication patterns. The insights gained from overlaying can be used for specifying variables and for hypotheses development. For example, if the overlaid representations are indicative of a pattern of appropriation (e.g., of a hot zone with high intensity of cursor moves), these indications may be quantitatively evaluated (by calculating relative ratios of visual action on the shared digital space) and tested in the form of hypotheses (step 7). Finally, the overall quantitative and qualitative results are critically interpreted (step 8 in Figure 2).

Insert Table 2 about here

Table 1 lists some potential research questions to be investigated with the help of the VRM. General questions, as for example “Has the discussion been productive?” (Question 1a in Table 1) may be answered based, inter alia, on the number of textual items documented on the 
shared digital space. The latter question may be investigated further by seeing whether any fluctuations in productivity can be observed during the discussion. The question of "How has the discussion evolved?” can be answered by examining the trajectory of the creation of textual items. One can also analyze which textual items were grouped, relocated, or deleted and why. Replay generated revelations about the intensity of modifications (deletions and re-writings) of discussion contributions are indicative of how confident the discussants were in their intellectual endeavour. The intensity of modifications is also indicative of how well coordinated the group knowledge work has been. It shows also how much “collaborative effort” (Clark \& Wilkes-Gibbs, 1986; Gergle, Kraut, \& Fussell, 2013, p.10) has been invested by the group to come up with the final output of the visual conversation.

The VRM can also help understand the final output of a workshop or a meeting. In case there are gaps in the final picture (e.g., on a filled visual template), there is no easier way to reveal why these gaps have formed than watching a replay recording. Further specific insights that can be obtained are related to "focus" - e.g., are there any "hot zones" where clustering of cursor moves has occurred, showing that the discussion has focused on certain topics? Discussion fluctuations can often be observed, which have steered the interaction towards focusing on certain topics. The replay recordings show which textual elements have been grouped and moved together and at which stage of the conversation. It can also be seen if these groupings have been thematic or the elements have been grouped following a collaborative insight. Discussion deviations can also be observed, for example after a "blocking” (Sonalkar, Abogunje, \& Leifer, 2013, p.106) occurring in the flow of the conversation. Time (in seconds or minutes) can be measured to see how long it has taken to resolve the blocking. 
The VRM can be used to replay the visual discussions and examine, for example, how $a$ plan has been constructed (with or without the help of a software-preloaded interactive template like a project plan diagram or a road map), how a collective rating has been established (e.g., with the help of a matrix, a pyramid, a relevance tree), or how a consensus has emerged (e.g., with the help of a Venn diagram). Further questions to investigate are, for instance, “How has a group understanding of a matter at hand been reached?" and "Are there any time-related or spatial connections between the textual items mapped on the shared digital space?”.

In case of pre-designed structure (when the researchers decide to use a software preloaded visual template like a matrix, fishbone chart, or an empty mind map), questions to investigate include: "Has the shared space been populated with contributions following the predesigned structure "faithfully" (DeSanctis \& Poole, 1994) or "unfaithfully?"” and "Do different visual structures lead to different group processes and outcomes?’.

Insert Table 3 about here

Table 3 lists some example hypotheses which could be tested with the VRM and their related measurements. Hypotheses related to the productivity of the discussion may be tested based, inter alia, on the number of textual items documented on the shared digital space. Hypotheses related to summarization (O’Donnell, Dansereau, \& Hall, 2002, p.71) and cognitive bucketing (Stigliani \& Ravasi, 2012, p.239) as activities displayed during the discussion may be tested based on the number of grouped textual items, as well as the patterns of their grouping. Hypotheses associated with coordinated directionality may be tested based on the trajectory of creation and modification of textual items. If grouped textual items are moved together on the shared digital space, the trajectory of their displacement may be indicative of thematic deviations in the discussion (see Figure 6). The actions per item ratio (i.e., how many actions were 
undertaken to finish one textual item) shows how much “collaborative effort” (Clark \& WilkesGibbs, 1986; Gergle et al., 2013, p.10) has been invested by the group to come up with the final output of the visual conversation. The cursor moves per item ratio (i.e., how many mouse cursor moves were undertaken to finish one textual item) is an indicator of coordination loss (Oslon, Malone, Smith, 2001). The lack of coordinated directionality is a sign that the group does not work harmoniously. The relative proportion of modifications is an indicator of reviewability and revisability (Clark \& Brennan, 1991) of contributions. If we measure the "time between actions”, we are actually measuring how much time the group spent thinking and discussing. The latter may be evidential in testing hypotheses related to the length of the discussion and the timing of contributions.

\section{MIXING QUAN AND QUAL - STAGES AND METHODOLOGIAL INTEGRATION}

The VRM utilizes a three-phase embedded MM design (see, e.g., Creswell \& Plano Clark, 2010; Tashakkori \& Teddlie, 2010). According to Leech and Onwuegbuzie (2009)’s and Teddlie and Tashakkori (2009)'s typologies of mixed methods research designs, our procedure can be qualified as a fully mixed equal status design - "fully mixed” because the integration is interdependent (in sequential tandems - steps $1 \rightarrow 2 \rightarrow 3,4 \rightarrow 5$, and $6 \rightarrow 7$ ) and occurs at the level of data collection and analysis (Ibid.; Curry, \& Creswell, 2013, p.2140; Jason \& Glenwick, 2015). "Equal status” because the quantitative and qualitative phases have equal weight, with no priority of the quantitative over the qualitative data or vice versa. Step 1 of our methodological procedure (see Figure 2) envisions parallel QUAN and QUAL data collection. Next, QUAN experimental and survey data are converted into narratives (qualitized - step 3). Further on (in step 5), the QUAL data from the replay recordings is quantitized with the help of the coding scheme (Table 2). The process of overlaying many replay diagrams (step 6) delivers condensed representations 
(Figure 4b) which are very informative regarding the patterns behind visual conversations and regarding which parts of the QUAN data is worth to be further analyzed statistically. Thus, the VRM utilizes an epistemologically acceptable procedure of data transformation which intuitively answers the question of “how to integrate” (Fetters \& Freshwater, 2015, p.115; Fielding, 2012, p.127) different types of data.

The way methods are corroborated and converged in the VRM resembles methodological eclecticism (Tashakkori \& Teddlie, 2010) and multi-genre crystallization (Richardson, 2000, p.934). Denzin (2012) speaks of “triangulation 2.0” technique which seeks to produce thick and complex interpretation. Similarly, VRM integrates by merging more than three sides - it integrates aspects from (a) postpositivist, pragmatist and participatory methods, and (b) retrospective, introspective and inspective methods (Figure 3). The VRM integrates knowledge claim positions by adopting empirical measurement from postpositivism (in the STDB), the practice orientation from pragmatism, and the empowerment orientation from participatory research.

\section{Insert Figure 3 about here}

Much like pragmatism, which is focused on real-world problems and consequences of actions (Creswell, 2003), the VRM is focused on real discussion actions and their consequences. As pointed out by Johnson, Onwuegbuzie, and Turner (2007), many (or most) mixed methods writers have argued for some version of pragmatism as the most useful philosophy to support mixed methods research. We believe that the VRM belongs to the "pragmatism of the middle" stream (Johnson et al., 2007, p.125) - being well positioned between "pragmatism of the left” (where "left" is not a political concept but implies antirealism and strong pluralism) and “pragmatism of the right” (where "right” implies a strong form of realism and a weak form of 
pluralism). The VRM envisions that the researcher and the discussants watch the replay recording (or parts of them) together after the discussion (step 3, Figure 2).

Figure 3b displays how integration of alternative "Weltanschauung” positions is accomplished with the VRM. In a sense, the VRM is a retrospective method, since it envisions reviewing the visual conversation in a qualitative follow-up (after the conversation has taken place). At the same time, the VRM is an introspective method, since the research subjects are being involved in a self-observation process while watching the replay recordings. The VRM is an inspective method as well, because it involves the employment of pre-designed (controlled) experimental conditions.

\section{THE VRM IN PRACTICE: AN EXAMPLE}

The VRM was first applied in a mixed-methods study with 186 managers. The MMRextended controlled experiment (Step 1) was in the context of experience sharing in small groups. Participants were given the task to share their project experiences. Groups of three discussants were randomly assigned to conditions which had different shared-space backgrounds (predesigned visual templates), in order to study the effect of the latter on the conversation processes and outcomes. Group discussions were screen recorded and coded according to the scheme ${ }^{2}$ shown in Table 2. Coded data was stored in a textual and numeric format (in a spatio ${ }^{3}$-temporal database - $\mathrm{STDB}^{4}$ ) and in a graphical format (in replay diagrams - see Figures 4, 5, and 6).

Figure 4a shows an example of a replay diagram which reveals a structured pattern of discussion contributions with few modifications. Figure 5 reveals an unorderly pattern of contributions with many modifications. These two examples of replay diagrams are informative in answering questions like $1 b, 1 c$, as well as $3 a$ and $3 b$ (see Table 1). The replay diagram in Figure 5 shows the filling pattern of a funnel template. The displayed trajectory is rather 
unstructured, with abrupt changes of direction and cursor movements that cross over large sections of the template.

\begin{tabular}{|c|}
\hline Insert Figure 4 about here \\
\hline Insert Figure 5 about here \\
\hline
\end{tabular}

Figure $4 \mathrm{~b}$ shows an overlaid representation of many replay diagrams. The overlay ${ }^{1}$ reveals a grid-like (predominantly vertical) pattern of cursor movement.

Insert Figure 6 about here

Figure 6 displays a final picture of a visual conversation (in which a matrix template was used) and its replay diagram. It can be seen in Figure 6b that six textual elements have been consequently moved to the right (actions 16 to 21), obviously following a collaborative insight. Figure $6 \mathrm{~b}$ also shows that a "blocking" has occurred in the flow of the conversation before the collaborative insight - the time before action 16 is close to one minute. This stands out as a long "time between actions" compared to the other time intervals. In fact, the revelations of a blocking followed by a collaborative insight, shown in Figure 6b, are capable of giving answers to research questions like $1 d, 1 e$, and $1 g$ (Table 1 ).

Figure 6a shows that the last column of the grid is empty. However, the replay diagram (Figure 6b) reveals that the "emptiness" of this area does not correspond to lack of activity. It can be seen that two textual items have been created (in actions 27 and 28) and subsequently deleted. Without the replay recording, the emptiness of this part of the visual template may be interpreted wrongly. The feedback we gathered during the qualitative follow-up (step 3 in Figure 2) revealed that some discussants were trying to fill in this part of the visual template for the mere purpose of 
not leaving it blank, while, in fact, the projects they had been involved in had encompassed no closing stages.

\section{DISCUSSION}

By using the power of visualization, the VRM aims at leveraging MM data integration (Fetters \& Freshwater, 2015, p.115; Fielding, 2012, p.127) to a new level, where visual synergy gains enable a "value added” research outcome. The integration of overlaid replay diagrams with quantitative analysis (steps 6 and 7 in Figure 2) offers a “ $1+1=3$ ” integration formula (Fetters \& Freshwater, 2015, p.116) - it permits to discover the patterns behind visual conversations, which would have remained invisible without the integrative visualization. The insights gained from the overlaid replay diagrams can be used for hypotheses generation, so that a macroconceptualization of how a visual conversation has evolved can be construed in the critical interpretation stage (step 8 in Figure 2).

According to Tashakkori and Creswell (2007, p.4) a quick comparison of the MM studies reveals that they utilize two types of data collection procedures (e.g., focus groups and surveys), two types of data (e.g., numerical and textual), two types of data analysis (statistical and thematic), and two types of conclusions (emic and etic representations, “objective” and “subjective,” etc.). In this line of thought, the VRM differs by a) introducing a third type of data collection procedure - the focus group supported by a replay recording, b) utilizing visual data, apart from textual and numerical, and (c) building on videographic statistical and thematic data analysis. The conclusions reached through the VRM are interactively intersubjective. Apart from being reached jointly (i.e., intersubjectively) by the researcher and the researched, the VRM conclusions are enhanced by the interactive reviewability features of the replay recordings. These recordings can be viewed at different speeds, paused and rewound, and easily searched for traces 
and clues. In such a way the VRM makes the output of group discussions "changeable and contestable” (Freshwater, 2013, p.300).

In fact, MMR research has long been focused on reducing the researcher-researched gap (Marti \& Mertens, 2014, p.209). This tendency has been subjected to criticism for "shaping utopias” (Ibid., p.209; see, e.g., Denzin, 2012) by handing complete control of the research process over to the researched subjects (Sullivan, Derrett, Paul, Beaver, \& Stace, 2014). We concur with the opinion that handling too much control over to the researched subjects can produce anecdotal results. We therefore adopt a "pragmatism of the middle” strategy for the VRM, in order not to empower the research subjects too much (or too little) (see "Mixing QUANT and QUAL” section). We listen carefully to the voices of our participants and we let them correct and enrich our findings. However, we also observe the authentic behavior of people during discussions, and retrieve our hypotheses and inferences based on authentic behavior.

In this manner, we are also aiming to mitigate another problem that MMR research has been at times accused of, namely the quality assurance problem (see Ivankova, 2013). According to Bergman (2008) many research designs run under the MMR banner, but consist of QUAN and QUAL components, which hardly connect in their conceptualization and execution. In such cases, the quality of meta-inferences derived from converting from one type of data to another (e.g., quantitizing qualitative data) becomes questionable (Wall et al., 2013, p.22). Leech, Dellinger, Brannagan, and Tanaka (2010, p.20) called this “a need for conversion legitimation”. The VRM offers a high level of conversion legitimation: QUAN-to-QUAL and vice versa conversions are made based on tightly connected steps (see Figure 2), based on visual (apart from textual and numeric) data, and the conclusions reached are interactively intersubjective. This "analytic 
density”' (Fielding, 2012, p.128) increases the depth of understanding reflected in the critical interpretation.

The VRM is applicable well beyond the field of MOS. For instance, the VRM can be applied as a technique to conduct visually-supported focus groups and interviews. The focus groups supported by replay recordings (step 3, Figure 2) belong to the family of the visual facilitation techniques. As such, they are capable of inducing a “depersonalization effect” (Comi et al., 2014, p.17) which may reduce biases related to group interaction (e.g., conformity pressure and groupthink). The VRM can be useful to elucidate the power dynamics in a group conversation - a simple secondary notation (e.g., color) identifying who of the discussants is contributing would allow to discern the patterns of power and privilege in the conversation. Moreover, the VRM can be applied as a “group mirror” (Jermann \& Dillenbourg, 2008) to elucidate the power dynamics in a group. Group mirrors (or group mirroring tools) provide a graphical representation of the group's actions which is dynamically updated and displayed to the collaborators (see Ibid.). With the VRM, the visually replayed group conversation is a group mirror - it is possible to replay, re-wind and watch parts of the visually documented conversation at any point of the discussion. Thus, a natural influx of self-reflective insights can be elicited from the discussants, in a dynamic flow, "beyond static [Ed.] projection” (Comi et al., 2014, 2014, p.1).

Some visual techniques for mapping dialogue that are presently used on paper (e.g., Roehl, Knuth, \& Magner, 2008) can be applied digitally, through the VRM. In communities on the downside of the digital divide, like communities where the dominant language in the country is not their first language, the universal visual language of the VRM can be used to overcome language barriers. Various visual templates can be employed as backgrounds of the shared digital 
space (for example, concept maps or argument maps on a facilitated tablet), to serve as structural canvases of the community dialogue.

The replay recordings constitute less of a "registering conservation” than a “reconstructable conservation”, as Bergmann, (1985, p.305) put it. Unlike photographs and diagrams, which are static (Crilly, Blackwell, \& Clarkson, 2006, p.2), the VRM builds on the feature of interactive reviewability. Researchers and participants can review (on their own or together) how the conversation has evolved, with eyes open for its fluidity and dynamics. This is a similar procedure to the video elicitation interview technique (Henry \& Fetters, 2012) with the difference that the content of the recording is not a video of the discussants but the screen capture of the discussants' shared digital space. With the VRM - in the case of some kind of predesigned structure, e.g., a software-embedded visual template - there is no need for indexing (unlike video analysis, which typically starts with indexing of data). The pre-designed structure contains ready indices, i.e., the guiding textual labels on the shared template or the visually distinct parts of the template.

The VRM offers a relatively unobtrusive way to observe human interactions. While video analysis is replete with psychological problems of exposure (the presence of a camera is annoying; watching an "image of self” is embarrassing), the VRM replay recordings do not involve images of humans and are emotionally neutral artifacts to review. Instead of causing deliberate behavior through camera movements, the VRM handles authentic behavior. The feeling of being observed is mitigated with the observation being performed through screen recording, which tends to be perceived as less obtrusive than the presence of a video camera. Furthermore, the VRM handles authentic behavior because it works based on a coding scheme (Table 2) developed "on the go" and evolving - while in fields such as computer supported work 
or human-computer interaction, there are more than 40 software programs for video interaction analysis available, all of which are based on predefined coding [Ed.] categories (Knoblauch \& Tuma, 2011). Finally yet importantly, the VRM is inexpensive and easily applicable - it only requires the use of a visual information system.

The VRM is, of course, not without limitations, the greatest limitation being the requirement to use a visual information system as a platform to perform the discussion through. In remote settings, however, this limitation is mitigated by the fact that using an online platform is necessary anyhow. Nevertheless, the use of a digital platform per se implies that the discussion may change compared to an unsupported conversation. Therefore the VRM is particularly suitable to run experiments comparing discussion processes and outcomes under different conditions (i.e., with different visual templates, different software interfaces, different group compositions), but it might be suboptimal for generalizing findings to unsupported conversations. The VRM requires no special technological experience or participants’ competence and is not necessarily inaccessible, even within communities on the downside of the digital divide. A tablet could be used to facilitate dialogue in such communities - some visual techniques that are successfully used on paper (see Roehl et al., 2008) can be utilized digitally, through the VRM.

\section{CONCLUSION}

In this paper we have proposed the VRM and shown its relevance for the MMR theory and practice. The unique characteristics of the VRM were outlined in relation to other methodological approaches as capturing authentic behavior, being suited for real-time use, etc. In the context of MMR, the uniqueness of the VRM was summarized as seeking to produce thick and complex interpretation through multi-genre integration (Figure 3). Again in the MMR context, the originality of the VRM was outlined as responding to the "integration challenge" 
(Fetters \& Freshwater, 2015) which the mixed methods community is facing. Potential application areas of the VRM (like planning, problem solving, etc.) were mapped in Table 1, with a reference to illustrative research questions, as well as illustrative hypotheses and their measurements (Table 3). Additionally, examples from a real application study were provided in Figures 4, 5, 6 and in the section “The VRM in Practice: an Example”.

With this paper we provide a contribution by developing a novel MMR technique which exploits recent technological developments, in particular in visual information systems, to analyze small group communication processes and outcomes. We introduced the VRM by offering instructive information (including potential software to be utilized) and providing a coding scheme for researchers who aim to use the VRM in future studies. The purpose of introducing the VRM is to open up new venues for researchers to answer novel questions which are not currently testable with existing techniques, and to do so credibly, by utilizing the scholarly accomplishments of MMR. 


\section{NOTES}

1. Overlaying can be technically performed with the help of any visual information system (e.g., Adobe Illustrator, let's focus) with embedded layer functionality.

2. We developed this coding scheme following the coding-scheme development procedure described in Sonalkar et al. (2013, p.98). The version of the coding scheme presented in Table 2 is the result from an iterative examination of 62 replay recordings.

3. To make spatial measurement possible, the shared digital space needs to be split into spatial zones. The zones must be identical for all analyzed (e.g., experimental) conditions (see Figure 2) but can be specific to each research project.

4. We have adopted the term "STDB” from Etienne and Devogele (2010, p.86). An example STDB is available from the authors on request.

\section{REFERENCES}

Archibald, M. (2015). Investigator Triangulation A Collaborative Strategy With Potential for Mixed Methods Research. Journal of Mixed Methods Research, (February), 1-23.

Balomenou, N., \& Garrod, B. (2015). A review of participant-generated image methods in the social sciences. Journal of Mixed Methods Research, (April), 1-17. 
Bell, E., Warren, S., \& Schroeder, J. (2014). The Routledge companion to visual organization. Routledge.

Bergman, M. (Ed.). (2008). Advances in mixed methods research: Theories and applications. SAGE.

Bergmann, J. (1985). Flüchtigkeit und methodische Fixierung sozialer Wirklichkeit: Aufzeichnungen als Daten der interpretativen Soziologie. In W. Bonss \& H. Hartmann (Eds.), Entzauberte Wissenschaft. Göttingen: Otto Schwarz.

Clark, H., \& Brennan, S. (1991). Grounding in communication. In L. Resnick, J. Levine, \& S. Teasley (Eds.), Perspectives on socially shared cognition. American Psychological Association, 127-149.

Clark, H., \& Wilkes-Gibbs, D. (1986). Referring as a collaborative process. Cognition, 22, 1-39.

Comi, A., Bischof, N., \& Eppler, M. (2014). Beyond Projection. Using Collaborative Visualizations to Conduct Qualitative Interviews. Qualitative Research in Organizations and Management: An International Journal, 9(2), 110-133.

Creswell, J. (2009). Editorial: Mapping the field of mixed methods research. Journal of Mixed Methods Research, 3(2), 95-108.

Creswell, J., \& Plano Clark, V. (2010). Designing and conducting mixed methods research. SAGE.

Creswell, J. (2003). Research Design: Qualitative, Quantitative, and Mixed Methods Approaches (2nd ed.). SAGE.

Crilly, N., Blackwell, A., \& Clarkson, P. (2006). Graphic elicitation: using research diagrams as interview stimuli. Qualitative Research, 6(3), 341-366.

Denzin, N. (2012). Triangulation 2.0. Journal of Mixed Methods Research, 6(2), 80-88. 
DeSanctis, G., \& Poole, M. (1994). Capturing the Complexity in Advanced Technology Use: Adaptive Structuration Theory. Organization Science, 5(2), 121-147.

Etienne L., Devogele T. (2010). Spatio-temporal Trajectory Analysis of Mobile Objects Following the same Itinerary. The International Archives of the Photogrammetry, Remote Sensing and Spatial Information Sciences, 38(II), 86-91.

Evertsson, N. (2015). A Nested Analysis of Electoral Donations. Journal of Mixed Methods Research, (May), 1-22.

Ewenstein, B., \& Whyte, J. (2007). Beyond Words: Aesthetic Knowledge and Knowing in Organizations. Organization Studies, 28(5), 689-708.

Fetters, M., Curry, L., \& Creswell, J. (2013). Achieving integration in mixed methods designs principles and practices. Health Services Research, 48(6 Pt 2), 2134-56.

Fetters, M., \& Freshwater, D. (2015). Editorial: The $1+1=3$ Integration Challenge. Journal of Mixed Methods Research, 9(2), 115-117.

Fielding, N. (2012). Triangulation and Mixed Methods Designs Data Integration With New Research Technologies. Journal of Mixed Methods Research, 6(2), 124-136.

Freshwater, D. (2013). Taking the Time and Trouble With Mixed Methods Research. Journal of Mixed Methods Research, 7(4), 299-301.

Gergle, D., Kraut, R., \& Fussell, S. (2013). Using Visual Information for Grounding and Awareness in Collaborative Tasks. International Journal of HCI, 28, 1-39.

Henry, S., \& Fetters, M. (2012). Video elicitation interviews: a qualitative research method for investigating physician-patient interactions. The Annals of Family Medicine, 10(2), 118-125. 
Isenberg, P., Elmqvist, N., Scholtz, J., Cernea, D., Ma, K., \& Hagen, H. (2011). Collaborative visualization: Definition, challenges, and research agenda. Information Visualization, 10(4), 10-326.

Ivankova, N., Creswell, J., \& Stick, S. (2006). Using mixed methods sequential explanatory design: From theory into practice. Field Methods, 18(1), 3-20.

Ivankova, N. (2013). Implementing quality criteria in designing and conducting a sequential QUAN $\rightarrow$ QUAL mixed methods study of student engagement with learning applied research methods online. Journal of Mixed Methods Research, 8(1), 25-51.

Jason, L., \& Glenwick, D. (Eds.). (2015). Handbook of Methodological Approaches to Community-Based Research: Qualitative, Quantitative, and Mixed Methods. Oxford University Press.

Jermann, P., \& Dillenbourg, P. (2008). Group mirrors to support interaction regulation in collaborative problem solving. Computers \& Education, 51(1), 279-296.

Johnson, R., Onwuegbuzie, A., \& Turner, L. (2007). Toward a definition of mixed methods research. Journal of Mixed Methods Research, 1(2), 112-133.

Jones, K. (2015). Using a Theory of Practice to Clarify Epistemological Challenges in Mixed Methods Research: An Example of Theorizing, Modeling, and Mapping Changing West African Seed Systems. Journal of Mixed Methods Research, 1-19.

Kearney, K., \& Hyle, A. (2004). Drawing out Emotions: The Use of Participant-Produced Drawings in Qualitative Enquiry. Qualitative Research, 4(3), 361-382.

Knoblauch, H., \& Tuma, R. (2011). Videography. An interpretative approach to video-recorded micro-social interaction. The SAGE Handbook of Visual Research Methods, 414-430. 
Leech, N., Dellinger, A., Brannagan, K., \& Tanaka, H. (2010). Evaluating mixed research studies: A mixed methods approach. Journal of Mixed Methods Research, 4(1), 17-31.

Leech, N., \& Onwuegbuzie, A. (2009). A typology of mixed methods research designs. Quality \& Quantity, 43(2), 265-275.

Leonardi, P. (2011). When flexible routines meet flexible technologies: Affordance, constraint, and the imbrication of human and material agencies. MIS Quarterly, 35(1), 147-167.

Lim, K., O’Connor, M., \& Remus, W. (2005). The Impact of Presentation Media on Decision Making: Does Multimedia Improve the Effectiveness of Feedback? Information \& Management, 42(2), 305-316.

Mack, N., Woodsong, C., MacQueen, K., Guest, G., \& Namey, E. (2005). Qualitative research methods: a data collectors field guide. FHI 360.

Marti, T., \& Mertens, D. (2014). Mixed Methods Research With Groups at Risk New Developments and Key Debates. Journal of Mixed Methods Research, 8(3), 207-211. Meyer, R., Höllerer, M., Dennis, D., \& van Leeuwen, T. (2013). The Visual Dimension in Organizing, Organization, and Organization Research: Core Ideas, Current Developments, and Promising Avenues. The Academy of Management Annals, 7(1), 489-555.

Miller, A. (2004). Video-cued recall: its use in a work domain analysis. In Proceedings of the Human Factors and Ergonomics Society Annual Meeting, Vol. 48, No. 15. SAGE, 16431647.

Minneman, S., \& Harrison, S. (1993). Where were we: making and using near-synchronous, prenarrative video. In Proceedings of the first ACM international conference on Multimedia, ACM, 207-214. 
Mondada, L. (2006). Video recording as the reflexive preservation and configuration of phenomenal features for analysis. In H. Knoblauch, J. Raab, H. Soeffner, \& B. Schnettler (Eds.), Video analysis, Bern: Lang, 51-68.

Nicolini, D., Mengis, J., \& Swan, J. (2012). Understanding the Role of Objects in CrossDisciplinary Collaboration. Organization Science, 23(3), 612-629.

O’Donnell, A., Dansereau, D., \& Hall, R. (2002). Knowledge maps as scaffolds for cognitive processing. Educational Psychology Review, 14(1), 71-86.

Oslon, G., Malone, T., Smith, J. (2001). Coordination Theory and Collaboration Technology. Mahwah, NJ: Lawrence Erlbaum Associates.

Pink, S. (2013). Doing visual ethnography. SAGE.

Quinlan, E., \& Quinlan, A. (2010). Representations of rape: transcending methodological divides. Journal of Mixed Methods Research, 4(2), 127-143.

Richardson, L. (2000). Writing: A method of inquiry. In N. Denzin \& Y. Lincoln (Eds.), Handbook of qualitative research. SAGE, 923-948.

Robinson, S., \& Mendelson, A. (2012). A Qualitative Experiment: Research on Mediated Meaning Construction Using a Hybrid Approach. Journal of Mixed Methods Research, 6(4), $332-347$.

Roehl, H., Knuth, M., \& Magner, C. (2008). Mapping dialogue: Essential tools for social change. Taos Institute Publications.

Rose, G. (2007). Visual methodologies: An introduction to the interpretation of visual materials (2nd editio). SAGE. 
Sonalkar, N., Abogunje, A., \& Leifer, L. (2013). Developing a visual representation to characterize moment-to-moment concept generation in design teams. International Journal of Design Creativity and Innovation, 1(2), 93-108.

Stewart, D., \& Stewart, C. (2001). Group Recall: The Picture-Superiority Effect With Shared and Unshared Information. Group Dynamics, 5(1), 48-56.

Stigliani, I., \& Ravasi, D. (2012). Organizing thoughts and connecting brains: material practices and the transition from individual to group-level prospective sensemaking. Academy of Management Journal, 55(5), 1232-1259.

Sullivan, M., Derrett, S., Paul, C., Beaver, C., \& Stace, H. (2014). Using mixed methods to build research capacity within the spinal cord injured population of New Zealand. Journal of Mixed Methods Research, 8(3), 234-244.

Tashakkori, A., \& Creswell, J. (2007). Editorial: The new era of mixed methods. Journal of Mixed Methods Research, 1(1), 3-7.

Tashakkori, A., \& Teddlie, C. (Eds.). (2010). Sage handbook of mixed methods in social \& behavioral research. SAGE.

Teddlie, C., \& Tashakkori, A. (Eds.). (2009). Foundations of mixed methods research: Integrating quantitative and qualitative approaches in the social and behavioral sciences. SAGE.

Vrkljan, B. (2009). Constructing a Mixed Methods Design to Explore the Older Driver-Copilot Relationship. Journal of Mixed Methods Research, 3(4), 371-385.

Wall, K., Higgins, S., Remedios, R., Rafferty, V., \& Tiplady, L. (2013). Comparing analysis frames for visual data sets using pupil views templates to explore perspectives of learning. Journal of Mixed Methods Research, 7(1), 22-42. 
Wheeldon, J. (2010). Mapping mixed methods research: Methods, measures, and meaning. Journal of Mixed Methods Research, 4(2), 87-102.

Yakura, E. (2002). Charting time: Timelines as temporal boundary objects. Academy of Management Journal, 45(5), 956-970.

Zeng, Z., Pantic, M., Roisman, G., \& Huang, T. (2009). A survey of affect recognition methods: Audio, visual, and spontaneous expressions. IEEE Transactions on Pattern Analysis and Machine Intelligence, 31(1), 39-58. 


\section{TABLES AND FIGURES}

Table 1. Illustrative Research Questions that can be addressed by Using VRM

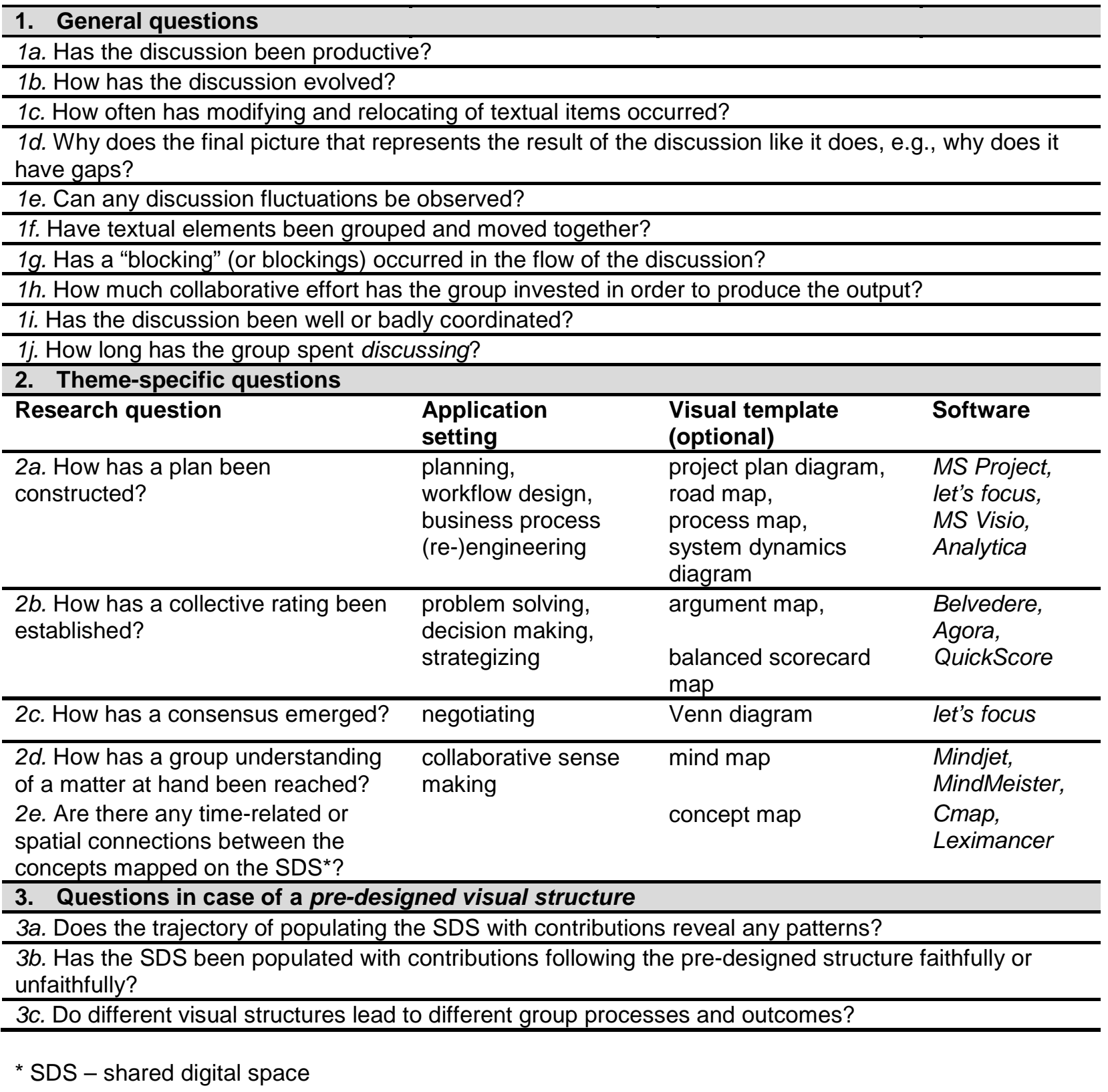


Table 2. Coding Scheme for Replay Analysis

\begin{tabular}{|c|c|c|c|c|c|c|c|c|}
\hline \multicolumn{3}{|c|}{ Textual item } & \multicolumn{2}{|c|}{$\begin{array}{l}\text { Textual item with } \\
\text { multiple bullet } \\
\text { points }\end{array}$} & \multicolumn{2}{|c|}{$\begin{array}{c}\text { Time between actions } \\
\text { (discussion time) } \\
\text { s (seconds) }\end{array}$} & \multicolumn{2}{|c|}{$\begin{array}{c}\text { Direction of cursor } \\
\text { movement } \\
\text { between actions }\end{array}$} \\
\hline \multicolumn{9}{|c|}{ Actions: } \\
\hline Create & Copy & $\begin{array}{l}\text { Modify: } \\
\text { extend } \\
\text { text }\end{array}$ & $\begin{array}{l}\text { Modify: } \\
\text { shorten } \\
\text { text }\end{array}$ & $\begin{array}{l}\text { Modify: } \\
\text { move* }\end{array}$ & $\begin{array}{l}\text { Modify: } \\
\text { delete }\end{array}$ & $\begin{array}{l}\text { Modify: } \\
\text { change } \\
\text { bullet-point } \\
\text { symbol }\end{array}$ & $\begin{array}{l}\text { Modify: } \\
\text { change } \\
\text { color of } \\
\text { text }\end{array}$ & $\begin{array}{l}\text { Modify: } \\
\text { resize } \\
\text { text }\end{array}$ \\
\hline$\theta$ & 国 & $\longrightarrow$ & 1 & 0 & $\times$ & & & $\uparrow$ \\
\hline
\end{tabular}


Table 3. Illustrative Hypotheses that can be tested by Using VRM

\begin{tabular}{|c|c|c|c|}
\hline \multirow{2}{*}{$\begin{array}{l}\text { ANOVA of } \\
\text { experimental treatment } \\
\text { on... }\end{array}$} & \multirow[t]{2}{*}{ Measurement } & \multicolumn{2}{|c|}{ Hypothesis related to... } \\
\hline & & $\begin{array}{l}\text { research } \\
\text { question } \\
\text { (RQ): } \\
\text { Table } 1\end{array}$ & $\begin{array}{l}\text { theoretical } \\
\text { construct }\end{array}$ \\
\hline number of textual items & $\begin{array}{l}\text { how many textual items are } \\
\text { documented on the SDS* }\end{array}$ & $\begin{array}{l}\text { RQ1a } \\
\text { RQ19 } \\
\text { RQ3c }\end{array}$ & $\begin{array}{l}\text { discussion } \\
\text { productivity }\end{array}$ \\
\hline number of groupings & $\begin{array}{l}\text { how many logical groupings of } \\
\text { textual items are documented } \\
\text { on the SDS }\end{array}$ & $\begin{array}{l}\text { RQ1f } \\
\text { RQ1e } \\
\text { RQ1d } \\
\text { RQ2e }\end{array}$ & $\begin{array}{l}\text { cognitive } \\
\text { bucketing, } \\
\text { summarization }\end{array}$ \\
\hline actions per item ratio & $\begin{array}{l}\text { how many actions were } \\
\text { undertaken to finish one textual } \\
\text { item (actions versus items) }\end{array}$ & RQ1h & $\begin{array}{l}\text { collaborative } \\
\text { effort }\end{array}$ \\
\hline $\begin{array}{l}\text { cursor moves per item } \\
\text { ratio }\end{array}$ & $\begin{array}{l}\text { how many mouse cursor moves } \\
\text { were undertaken to finish one } \\
\text { textual item (arrows versus } \\
\text { items) }\end{array}$ & RQ1i & $\begin{array}{l}\text { coordination } \\
\text { loss }\end{array}$ \\
\hline $\begin{array}{l}\text { relative proportion of } \\
\text { modifications }\end{array}$ & $\begin{array}{l}\text { how many modifications were } \\
\text { undertaken compared to all } \\
\text { actions (modify actions versus } \\
\text { all actions) }\end{array}$ & $\begin{array}{l}\text { RQ1c } \\
\text { RQ1d } \\
\text { RQ1e }\end{array}$ & $\begin{array}{l}\text { reviewability } \\
\text { and revisability }\end{array}$ \\
\hline \multirow[t]{2}{*}{$\begin{array}{l}\text { relative proportion of } \\
\text { faithful action sequences }\end{array}$} & $\begin{array}{l}\text { degree of overlap of the } \\
\text { trajectory of creation and } \\
\text { modification of textual items with } \\
\text { the ideal path (ratio of faithful } \\
\text { action sequences) }\end{array}$ & $\begin{array}{l}\text { RQ1b } \\
\text { RQ3a } \\
\text { RQ3b } \\
\text { RQ3c }\end{array}$ & $\begin{array}{l}\text { coordinated } \\
\text { directionality }\end{array}$ \\
\hline & $\begin{array}{l}\text { e.g., trajectory of } \\
\text { relocation of grouped } \\
\text { items: how were grouped } \\
\text { textual items moved } \\
\text { together on the SDS }\end{array}$ & $\begin{array}{l}\text { RQ1e } \\
\text { RQ1f } \\
\text { RQ2e }\end{array}$ & $\begin{array}{l}\text { thematic focus } \\
\text { of discussion, } \\
\text { thematic } \\
\text { deviations, } \\
\text { collaborative } \\
\text { insights }\end{array}$ \\
\hline discussion time & $\begin{array}{l}\text { discussion time spent to } \\
\text { produce the group output (time } \\
\text { between actions) }\end{array}$ & $\begin{array}{l}\text { RQ1j } \\
\text { RQ2e }\end{array}$ & $\begin{array}{l}\text { length of actual } \\
\text { discussion, } \\
\text { timing of } \\
\text { contributions }\end{array}$ \\
\hline
\end{tabular}

* SDS - shared digital space 

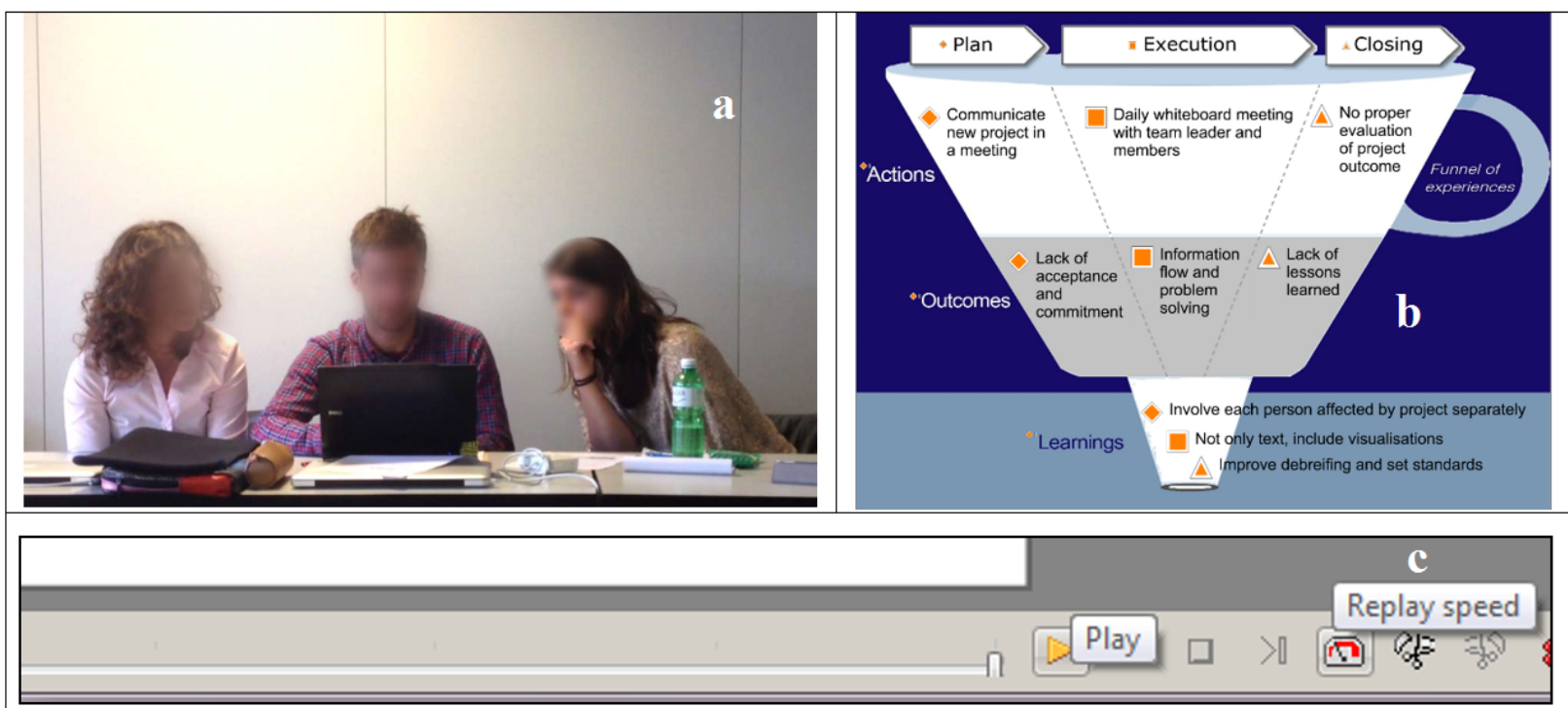

Figure 1. Basic Terms Used in this Paper: a) Discussants, b) a Visual Conversation mapped on a

Shared Digital Space (on a Funnel Visual Template), c) an Embedded Screen Recording

Functionality of a Visual Information System (the let's focus suite) 


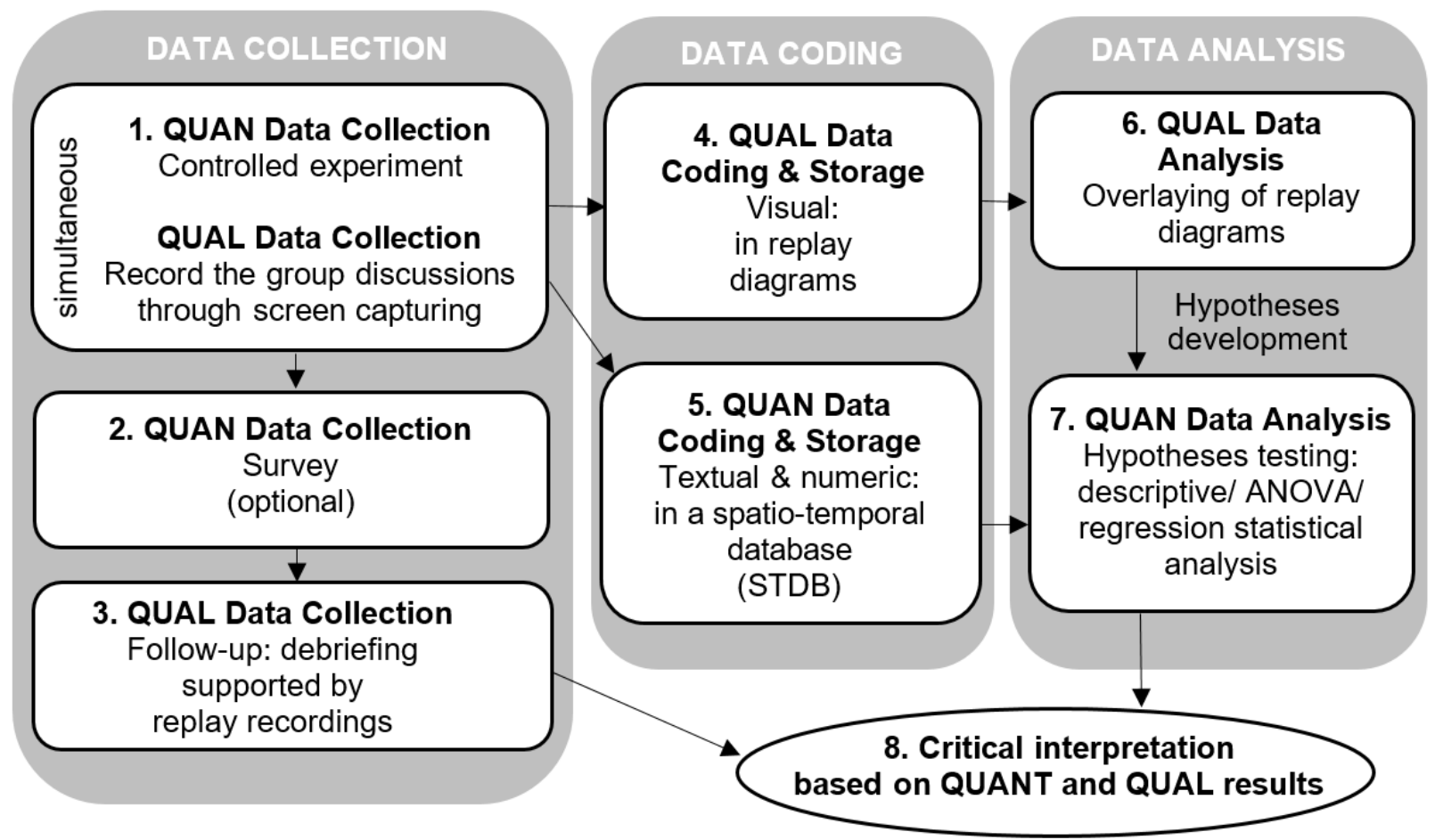

Figure 2. Summary of QUAN and QUAL Steps for Using the Visual Replay

Methodology (VRM) 

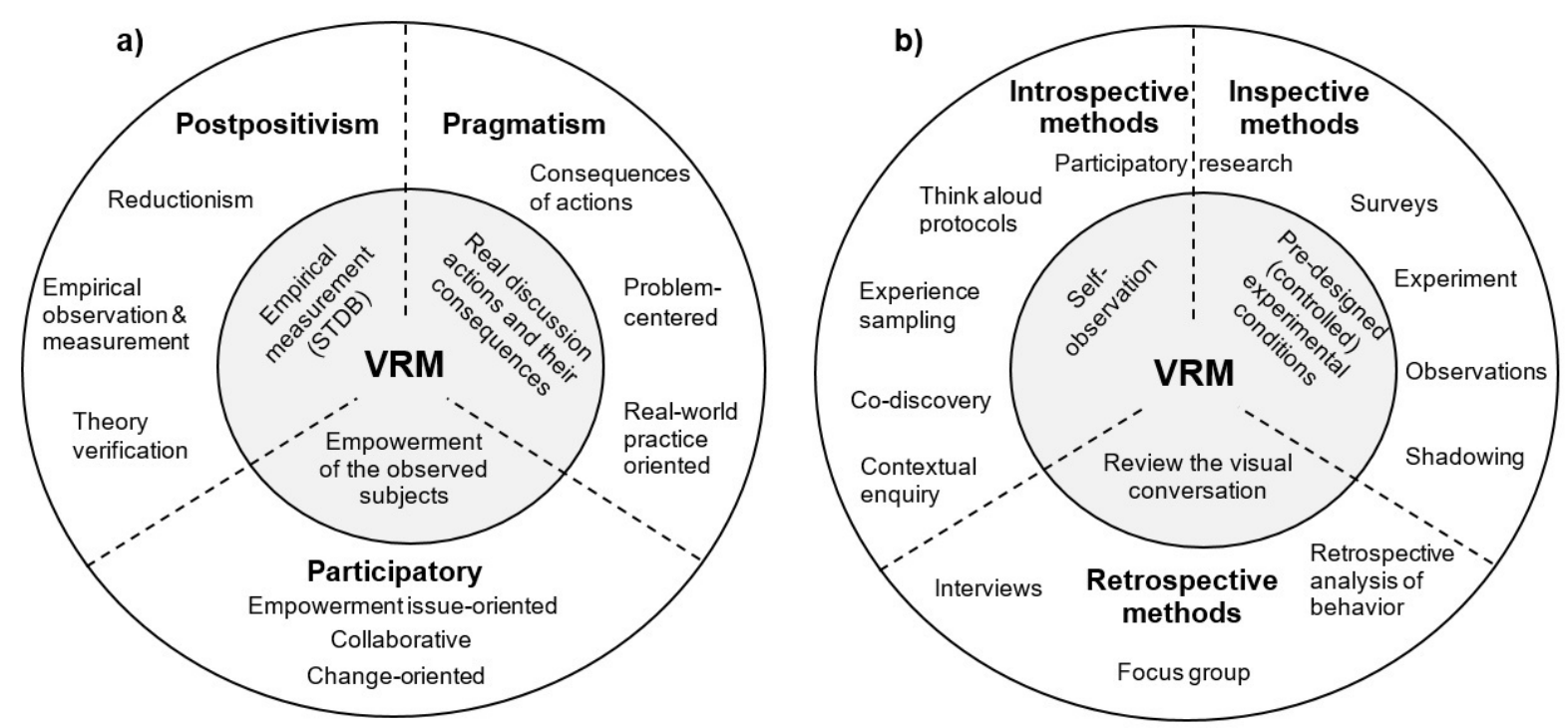

VRM: Visual Replay Methodology

Figure 3. Integration of (a) Alternative Knowledge Claim Positions (adapted from

Creswell, 2003, p.6) and (b) Alternative "Weltanschauung” Positions in the VRM 


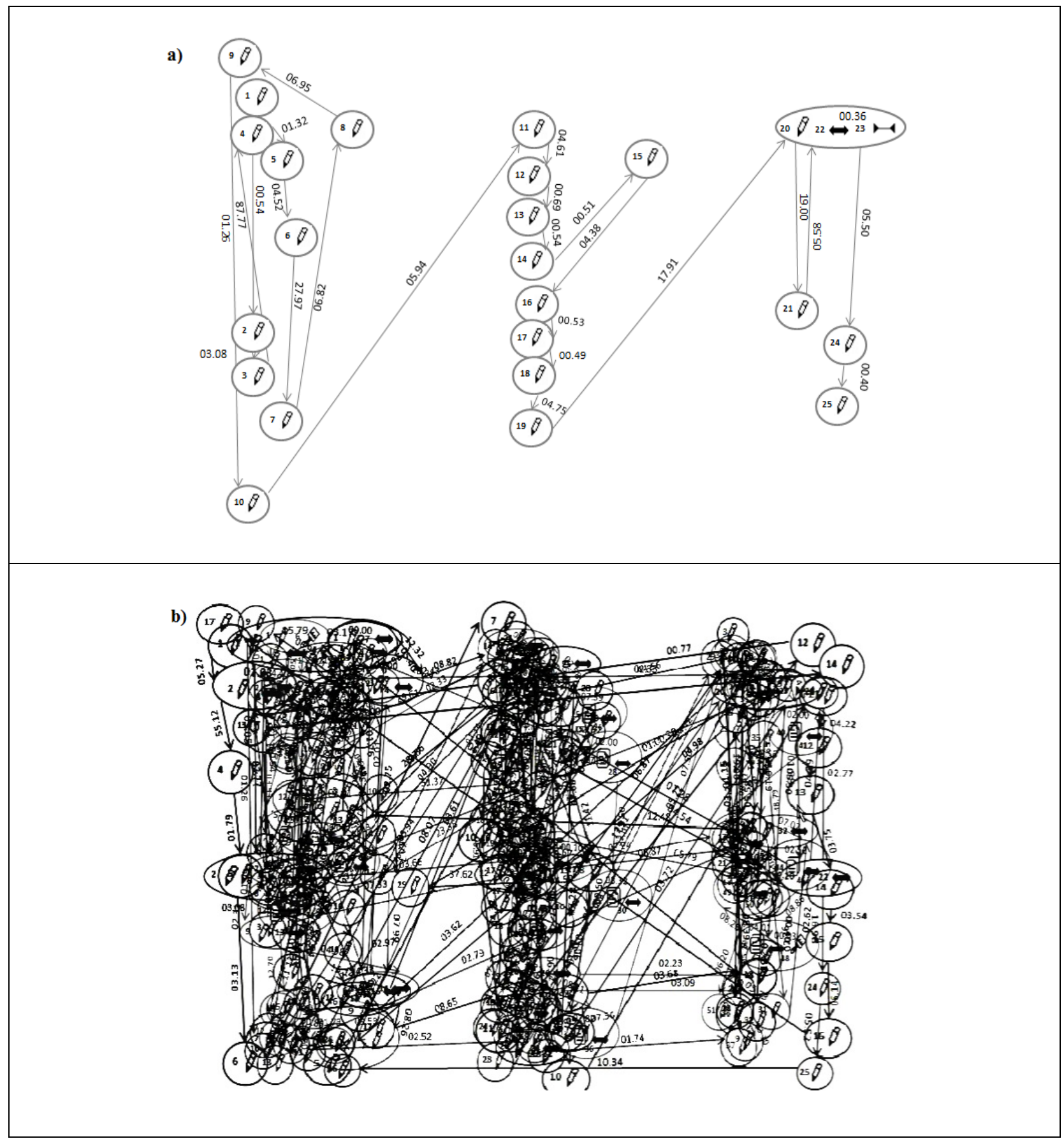

Figure 4. a) A Replay Diagram Showing a Structured Pattern of Discussion Contributions

with Few Modifications, b) Overlay Representation of Many Replay Diagrams Revealing a Gridlike Pattern 


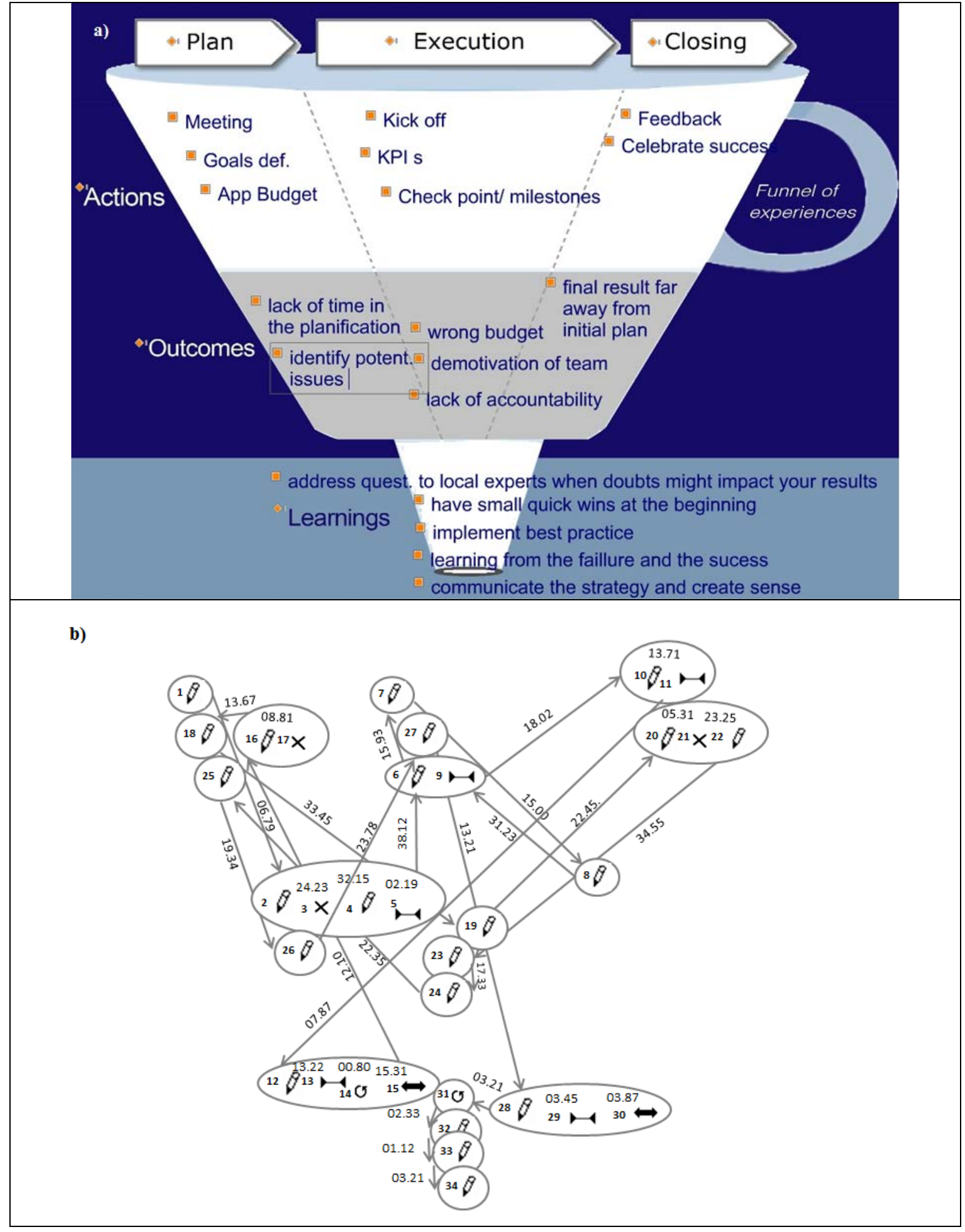

Figure 5. A Replay Diagram Showing the Filling Pattern of a Funnel Template 
(a) Final picture of a visual conversation

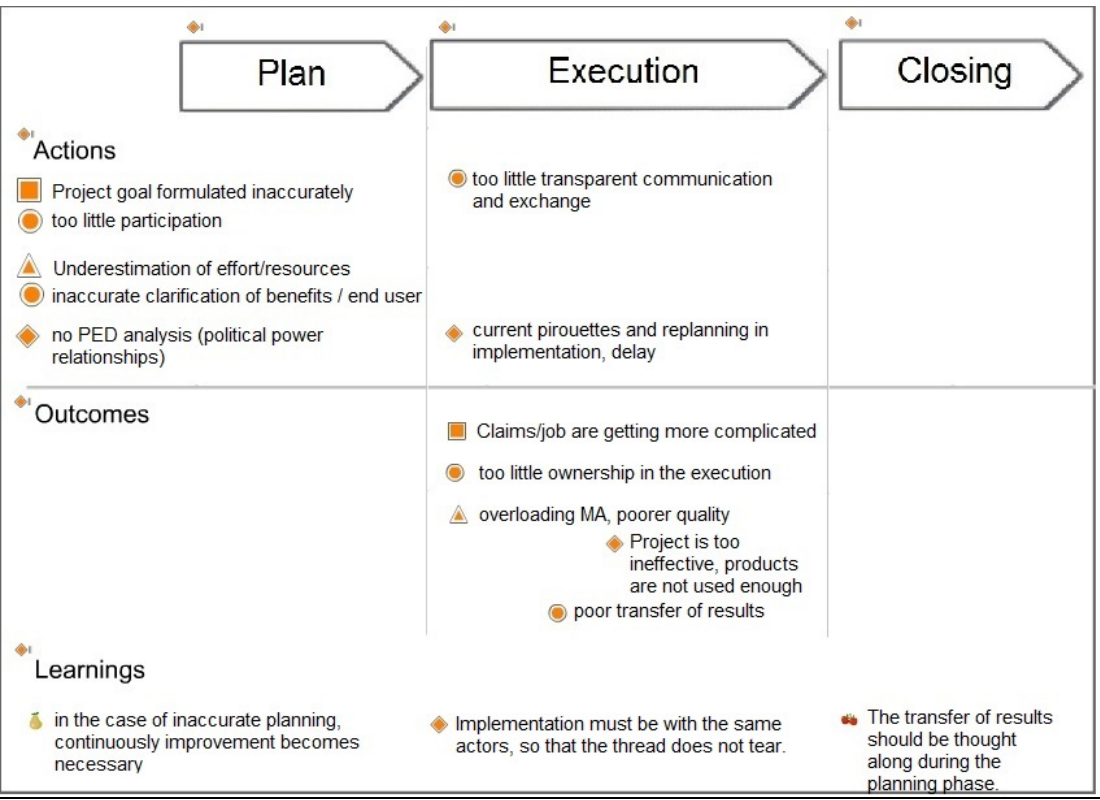

(b) Replay diagram

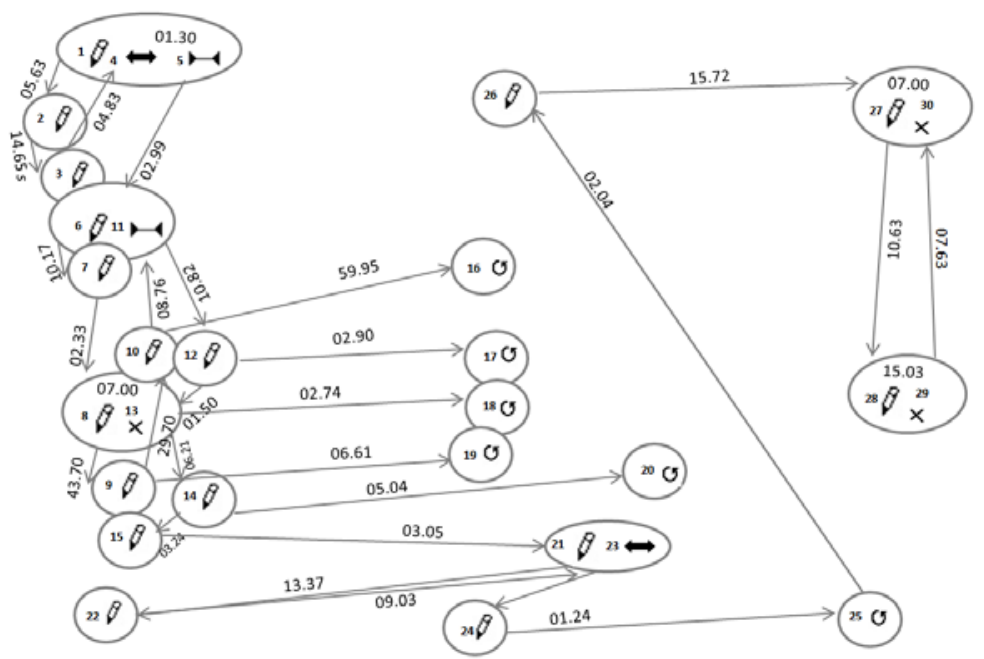

Figure 6. An Observed “Aha Effect” Revealed through a Replay Diagram 